\title{
AC 2008-2278: COLLABORATIVE PRODUCT DESIGN AND REALIZATION IN MECHANICAL ENGINEERING TECHNOLOGY CURRICULA
}

\section{Vukica Jovanovic, Purdue University, West Lafayette}

Vukica Jovanovic began her academic career in 2001 when she graduated at University of Novi Sad, majoring in Industrial Engineering and Management, Minor in Mechatronics, Robotics and Automation. She was working as Graduate Research and Teaching assistant and lectured various courses at departments of Industrial Engineering, Mechanical Engineering and Mechatronics from 2001 until 2006. She was an active member European organizing committee of student robotic contest Eurobot and chief of Eurobot organizing committee of Serbian student national competition in robotics. In the summer of 2002, she had an internship in an aircraft manufacturing company Embraer, in the part of the company Gamesa Aeronautica, section Moasa Montajes, Spain where she worked in product distributed environment. After graduating with a Master of Science (M. S.) degree, in area of Industrial Engineering, specialization in Production Systems in 2006, M.S. Jovanovic subsequently continued to work towards her Doctor of Philosophy $(\mathrm{PhD})$ degree at Purdue University, department of Mechanical Engineering Technology. She is currently working as a Graduate Research Assistant in Product Lifecycle Management Centre of Excellence Laboratory at Purdue University. As a graduate student, she is involved in the following projects: Society of Manufacturing Engineers Education Foundation Project: Product Lifecycle Management Curriculum Modules and National Science Foundation project: Midwest Coalition for Comprehensive Design Education. She is a student member of the American Society of Engineering Education, Society of Manufacturing Engineers (SME), Society of Woman Engineers (SWE), and Woman in Technology (WIT). She published two chapters in two textbooks, two journal articles and presented 23 conference papers. Her current research focuses on product lifecycle management and digital manufacturing.

\section{Mileta Tomovic, Purdue University}

Dr. Mileta M. Tomovic is W. C. Furnas Professor of Enterprise Excellence, Mechanical Engineering Technology Department, School of Technology, Purdue University. He is Special Assistant to Dean for Advanced Manufacturing, Purdue University Scholar, Director of Digital Enterprise Center and co-director of Purdue University PLM Center of Excellence. He received his B.S. degree in Mechanical Engineering from the University of Belgrade, Yugoslavia, in 1979, M.S. degree in Mechanical Engineering from the Massachusetts Institute of Technology in 1981, and Ph.D. in Mechanical Engineering from the University of Michigan, Ann Arbor in 1991. Dr. Tomovic is recognized nationally and internationally as a leader in mechanical engineering technology education and for his scholarly contributions to the field of design for manufacturability. Dr. Tomovic has fifteen years of teaching experience at Purdue University, with emphasis on teaching manufacturing and design courses, conducting applied research, and engagement with Indiana industry. Dr. Tomovic co-authored one textbook on materials and manufacturing processes, adopted by over 50 national and international institutions of higher education. He has authored or co-authored over 50 papers in journals and conference proceedings. Dr. Tomovic made over 20 invited presentations nationally and internationally on the issues of design optimization and manufacturability. He has co-authored four patents, and over 60 technical reports on practical industrial problems related to product design and manufacturing process improvements. Dr. Tomovic's research interests are in the area of advanced manufacturing, design optimization, collaborative design, product lifecycle management, modeling of rapid prototyping and fast free form fabrication methods, web-based multi-user platform development for industrial tooling and customer-supplier resource management, and deployment and commercialization methodology for highly focused software tools. He has received funding from the Department of Defense, Indiana 21st Century Technology Fund, National Science Foundation, Department of Energy, Purdue Research Foundation, and other sources. Dr. Tomovic has been a PI or Co-PI on several funded competitive grants exceeding \$12 million. Dr. Tomovic has been actively involved with local industry through the Technical 
Assistance Program (TAP). He has assisted over 100 different companies across Indiana on problems related to automation, manufacturing, and product and process design. The estimated value to Indiana industry, resulting from Dr. Tomovic's recommendations, exceed \$6 million over the ten years that he has been actively engaged with the TAP. In 2002, Dr. Tomovic received the Republican Gold Medal for Entrepreneurship, in recognition for his contributions to industry and for his entrepreneurship efforts, and also the American Metalcasting Consortium Director's Award for his contributions to the metalcasting field.

\section{Richard Mark French, Purdue University}

Mark French was trained as an aerospace engineer, earning his BS in aerospace and ocean engineering at Virginia Tech in 1985. We went on to earn his MS and Ph.D., both in aerospace engineering, from the University of Dayton in 1988 and 1993 respectively.He came to Wright-Patterson AFB in 1985 as a civilian research engineer and worked there full time until 1995. His areas of work included aeroelasticity, multi-disciplinary optimization and photomechanics.He left civil service in 1995 to work in the automotive industry where his field of specialty was noise and vibration. There he worked as both an engineer and a lab manager. He joined the Department of Mechanical Engineering Technology at Purdue University in 2004. He has taught courses in strength of materials, experimental strength of materials, dynamics, optimization and manufacturing stringed musical instruments. Degree(s):Bachelor of Science, Aerospace and Ocean Engineering/1985 - Virginia Tech Masters of Science, Aerospace Engineering/1988 - University of Dayton, Ph.D., Aerospace Engineering/1993 - University of Dayton. Industrial \& Business Experience:Senior Engineer, Robert Bosch Corporation, 1999-2004, Manager, Lear Corporation, 1995-1999, Research Engineer, Wright-Patterson AFB, 1985-1995 


\title{
Collaborative Product Design and Realization in Mechanical Engineering Technology Curricula
}

\begin{abstract}
Mechanical and manufacturing engineers are working in a global environment which requires new skills. New term developed over the last decade for them: the "knowledge workers". Those engineers need a new skill set to work successfully on collaborative projects involving people located not only at different companies, but also potentially on different continents. This new skill set can be developed using secure web sites for storing product related data, virtual chat rooms which would enable students to share presentations and applications. Those tools could enable faster collaboration on those projects. They could save that information as knowledge for their future capstone projects and alike. Working around the clock has recently become the goal of every company. Collaboration needs to be facilitated by digital means such as web portals, voice over internet protocol, and video and audio conferencing. Mechanical Engineering Technology students should be able to adapt quickly into this new working environment after their graduation. The student projects should involve working on web-based collaborative projects. Midwest Coalition for Comprehensive Design Education, National Science Foundation founded project, various projects were developed in the web based collaborative environment.
\end{abstract}

\section{Introduction}

Currently, engineers do not necessarily work at one location. With this disparate work environment engineers need to share product related data among themselves. The old-fashioned way of using blueprints, face to face meetings or travelling from one place to another is slowly being integrated with other digital technologies such as: computer aided design, product data management, and product lifecycle management, etc. The design and realization of contemporary products involve working in a digital collaborative environment. All productrelated processes, from design, prototyping, manufacturing, testing, and assembly, can be performed in more than one facility. As businesses expand globally, extensive collaboration during every phase of the product lifecycle is necessary for updated information and to provide data among different departments. Working in a distributed environment does pose some unique challenges. Managing distributed projects can be more complex than managing the projects in which people are working in the same office or in the same company. Keeping up with the pace that is going on in every stage of the project is becoming a full time job. Users need better, more collaborative tools that can empower innovation and success. It is difficult to gather a distributed workforce together in one room or even on one conference call. Today's global economy is in transition to a knowledge economy, or an information society. The "know how" is becoming more critical than economic recourses ${ }^{1}$. New technologies have had a significant impact on the way business is conducted, and have also changed the skills required by today's workers. Product design and realization is now shifting toward mass customization and a shorter product lifecycle. This requires more educated people and more flexible systems. Managing virtual meetings and distributed tasks needs a new skill set that should be fully covered in the Mechanical Engineering Technology Curriculum. 


\section{Midwest Coalition for Comprehensive Design Education}

The partner institutions involved in the project Midwest Coalition for Comprehensive Design Education are Purdue University and four two-year schools: Sinclair Community College, Fox Valley Technical College, Mott Community College, and Butler County Community College, as shown in Figure 1.

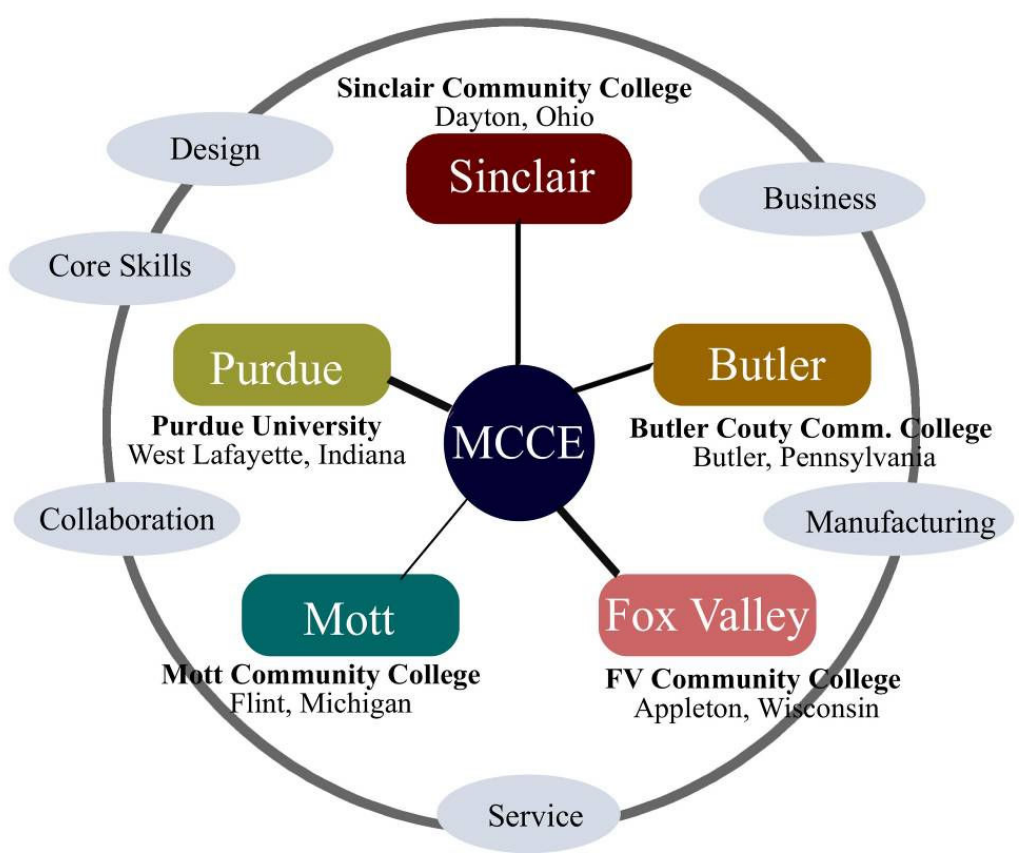

Figure 1: Midwest Coalition for Comprehensive Design Education

The project has the following objectives:

1. Validate the competencies for comprehensive design as they pertain to associate degree technicians and baccalaureate degree engineering technology students, as well as the existing and incumbent workforce.

2. Develop an interdisciplinary comprehensive design program between partner institutions. Address transferability of skills and knowledge from associate degree to baccalaureate degree programs in the area of comprehensive design.

3. Develop and deliver educational modules to associate degree technicians and baccalaureate degree technology students to increase their skill level and their competitiveness in the global marketplace. Address the competency gaps/skill needs as identified by the Society of Manufacturing Engineers.

4. Develop an educational program in comprehensive design focused on the existing and incumbent workforce. Develop methods for delivering educational modules to industry and existing workforce through existing continuous education programs.

5. Develop an outreach program for high school students. Address the issue of increasing visibility of the engineering and manufacturing profession and academic preparedness among the high school population. 
The project has the following outcomes:

1. To integrate critical and systematic approaches in design analysis and innovative methods in product development; to understand business considerations needed to produce products with superior quality.

2. To develop the ability to employ state-of-the-art technology in product and process development.

3. To develop skills to support product realization, including communications, technical writing, and customer needs analysis.

4. To learn independently and continuously as a lifelong learner, and to work effectively in a global team environment.

5. To develop awareness of professional ethics and social responsibilities to develop methods necessary to achieve quality.

\section{The Current Stage of the Project}

The first phase of the project was related to the identification of core competencies related to the area of Product Design and Realization. The plan of study that covers the transferability between AS and BS programs has been developed. The skill sets for comprehensive design in both AS and BS programs and the differential skill set required for transfer between AS and BS programs were defined as well. The collaborative tools have been tested on the following projects: Hand Drill, Guitar Manufacturing and Testing, and Radio Flyer. The team is currently developing an interdisciplinary comprehensive design program model.

Currently the integrated courses that cover necessary areas related to the Product Design and Realization are being developed between partner institutions. Web-based course/module support materials are also being developed.

The next phase would be related to the integration of the comprehensive design curriculum into the existing academic program, development of workforce training and development of an outreach program via existing pre-college outreach programs at partner institutions.

\section{Product Design and Realization and Global Working Environment}

Product design and realization includes the whole spectrum of conceptualization, detailed design, analysis, simulation, and prototyping. In collaborative design, multidisciplinary teams participate in design decision-making. Product information is shared across enterprise boundaries in an Internet-enabled distributed environment. Product and process development is a very complicated engineering process with strong interactions among its development tasks, and requires iterative discussion to communicate and coordinate the redesign process.

Product design and realization has to be supported by implementation of Product Lifecycle Management (PLM). PLM is a business strategy which integrates all information about the product from all stages of its lifecycle.

Those stages involve:

- Ideation and innovation, (advanced engineering);

- Business planning;

- Program planning; 
- Design and prototyping (product engineering);

- Process planning and sourcing (manufacturing engineering);

- Simulation and digital manufacturing (product validation);

- Manufacturing and assembly (manufacturing production); and

- Service, maintenance and distribution (service and warranty management).

Many manufacturing companies are operating in a global distributed environment. All those processes rely on an interaction and communication among the employees who are located in the wide spread companies. Those teams can include people with the various backgrounds, different cultures and varying working styles. Collaboration is different in that it uses digital tools rather than people. Some problems will probably occur in the first stage of the collaboration.

Overcoming the software barrier is the first step of making this collaboration possible. Managing projects with people who have different operational systems, different rights related to the administrative operations that are required for setting up the collaborative environment is another problem that needs to be resolved at the beginning of collaborative project (Figure 2). An example of such distributed projects is car and airplane design, production, assembly and maintenance.

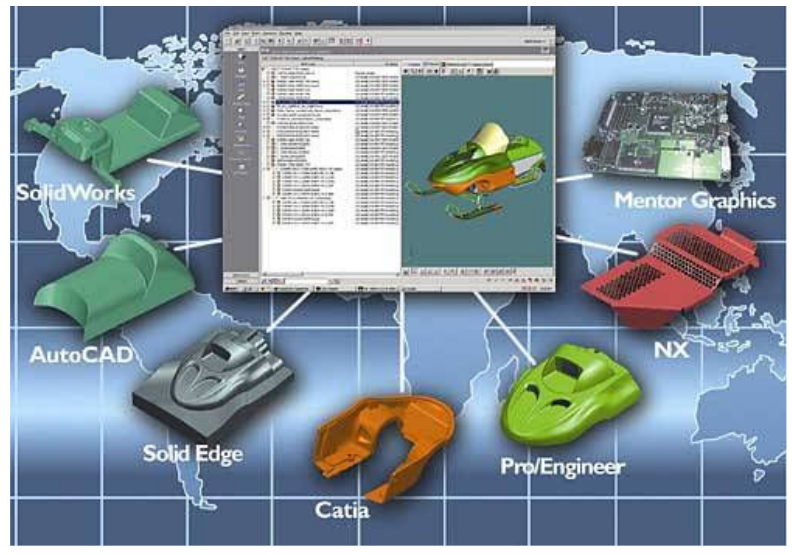

Figure 2: Collaborative Engineering (Teamcenter Engineering) ${ }^{7}$

Major aerospace companies are located on different continents. Working in that kind of environment requires extensive costs related to travelling and communication of team members. Operating businesses in different countries, outsourcing with different time zones needs other forms of communication. Collaboration can take a significant portion of overall project time. People who are working in a distributed environment on high-pressure projects feel the need to work around the clock. The engineers should have some new skills in order to do their job in this new, opened marketplace. Highly skilled people are required for communication at this global level of manufacturing. Knowing how to manufacture is not the only thing that is important. Engineers must also learn how to communicate with the people from those diverse teams. Those employees should be capable of communicating with digital means. Highly skilled workers who are capable of adapting quickly to new conditions are necessary for making the modern production work. 


\section{Collaborative Engineering and Technological Literacy}

International Technology Education Association (ITEA) identified the term "technological literacy". In order to be a technologically literate citizen, a person should understand what technology is, how it works, how it shapes society and in turn how society shapes it. Moreover, a technologically literate person has some abilities to "do" technology that enables them to use their inventiveness to design and build things and to solve practical problems that are technological in nature. A characteristic of a technologically literate person is that they are comfortable with and objective about the use of technology neither scared of it nor infatuated with it ${ }^{8}$. One of the required skills, according to this study, is know how to develop an understanding of and be able to select and use information and communication technologies. Advanced e-learning tools are offering employees the ability to participate in required or assigned training courses remotely and at their convenience. This on-demand model benefits training managers because it reduces the costs of in-person training and creates training options that are more accessible to employees. Additionally, training managers can create online learning portals with customized training schedules, list employee-specific requirements, certification renewal dates and other important information. Such portals reduce the number of inquiries and help manage the process for all employees, not just remote workers ${ }^{9}$.

\section{Collaborative Engineering and Technology Curricula}

Some professors are searching for the ways to adapt engineering curricula into the global era. Technology schools are preparing their graduates for a world where understanding foreign markets and mores have shifted from elective course to prerequisite skill. One example of a product design during the Web-based delivered lectures through one design exercise in crosscultural teams is shown in Figure $3^{10}$.

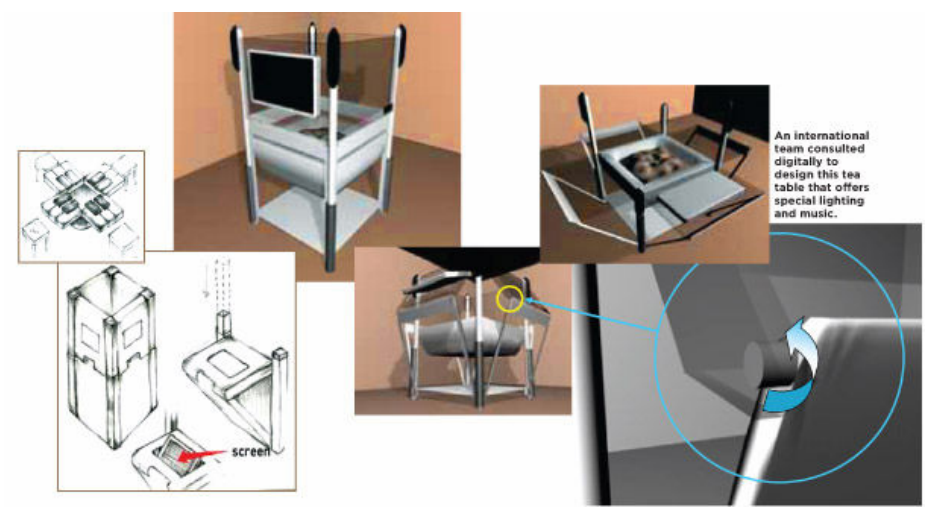

Figure 3: Product designed by student international team ${ }^{10}$

PLM data can be shared with global teams and external partners at any point in the product development process. In this way, users could capture the organizational knowledge and promote it into their corporate product knowledge warehouses (such as PDM, ERP, or legacy systems) where it can be managed and reused. Integrated visualization could enable viewing, markup, and analysis of data from any of the corporate or neutral CAD, and other office document formats. All team members can view and interact with the virtual product without having to learn to use a 
CAD system. In this way, 3D models can be used by supervisors and decision makers who do not necessarily have to use CAD software in order to understand the product structure. Visual presentation gets everyone on the same page to reduce the time and costs associated with understanding and resolving engineering issues. Integrated visual documents and application sharing conference capabilities allow globally dispersed product teams to review design issues and product concerns in real-time. These capabilities let team members quickly identify problems and reach mutual decisions, thus saving time, and minimizing the need for travel ${ }^{7}$.

\section{MCCDE: Collaborative Projects}

The partner institutions on the project are working collaboratively to identify, develop and deliver a curriculum that will integrate comprehensive design education across associate degree technician and baccalaureate degree technology colleges, to increase the skill level in the manufacturing sector. They are developing instructional modules for traditional and nontraditional student populations. The partner institutions are having regular meetings and videoconferences through which they were involved in the following collaborative projects: The Drill Project, Radio Flyer Project, and Guitar Project.

\section{The Drill Project}

Working in collaborative environment has been tested on a reverse collaborative engineering project of a cordless hand drill (Figure 4). The project was led by Purdue University (West Lafayette, Indiana) graduate students who were not working in the same office during their collaboration. The main purpose of the project was to establish the way how the future teams would collaborate on future projects. Different institutions have different software, just like it really happens in industry. Design teams have to face the problems related to the different licensing issues and at the same time they are developing and manufacturing new products. Some people are also using design related information even if they are not proficient in some Computer Aided Design (CAD) tools or they may not necessarily have some of those tools installed. Institutions had to figure out how they will work on designing together before starting with any complex products. Different software was tested as well as different neutral formats.

The first step was how to divide this product in sub-assemblies. There were three team members who were assigned for this task, so the logical sequence was to divide the product into the three sub-systems. This product, a hand drill, has been divided into the three sub-assemblies: a motor sub-assembly, switch sub-assembly, and housings (left and right), as shoen in Figure 4. Motor sub-assembly was designed using UGS NX, Switch sub-assembly was designed in SolidWorks, and housings were design in CATIA Generative Shape Design.

In real time projects, companies experience the same problems. The most desirable situation for CAD interoperability would be that every user involved is using the same CAD application. This scenario, if realized, removes all issues associated with interoperability. However, this is extremely difficult to implement in a real world. While a small enterprise that manufactures less complex products or who make all parts in-house could standardize the CAD application, it's almost impossible for large manufacturers who are developing complex products and who have to outsource a considerable number of the components (like automotive or aircraft industry) to standardize CAD tool over its entire supply chain ${ }^{10}$. 


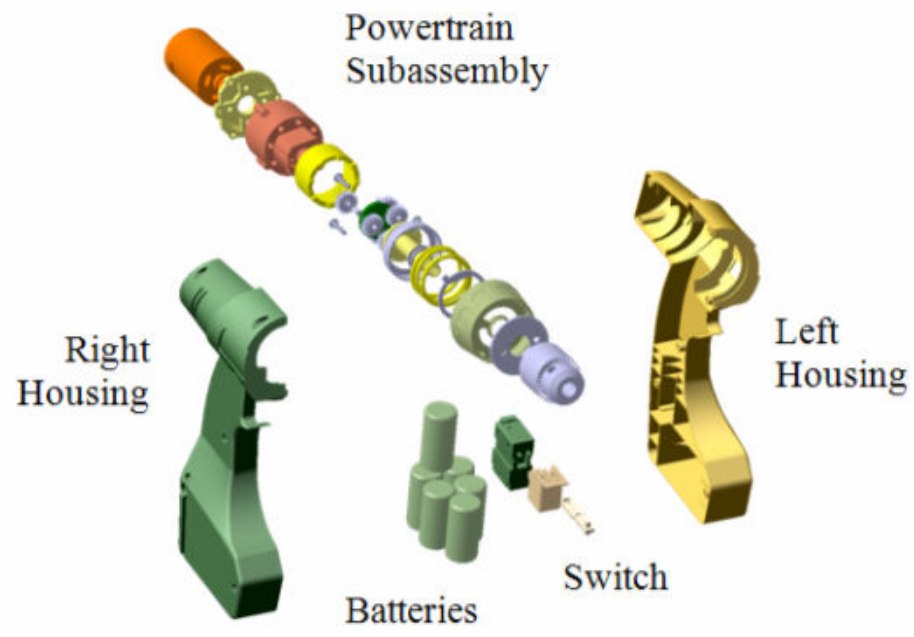

Figure 4: Explode state of a cordless drill

Teamcenter Community portal was used for sharing files among the team members. They were using MSN Messenger while discussing some things that ought to be done. Web Portals can provide an organized workplace for data sharing and storing important information. Object versions and change histories can be stored and reused again after the project is completed. In this way, important data can be captured. Figure 5 shows an example of using the Web Portal (in this case UGS Teamcenter) during this reverse engineering project.

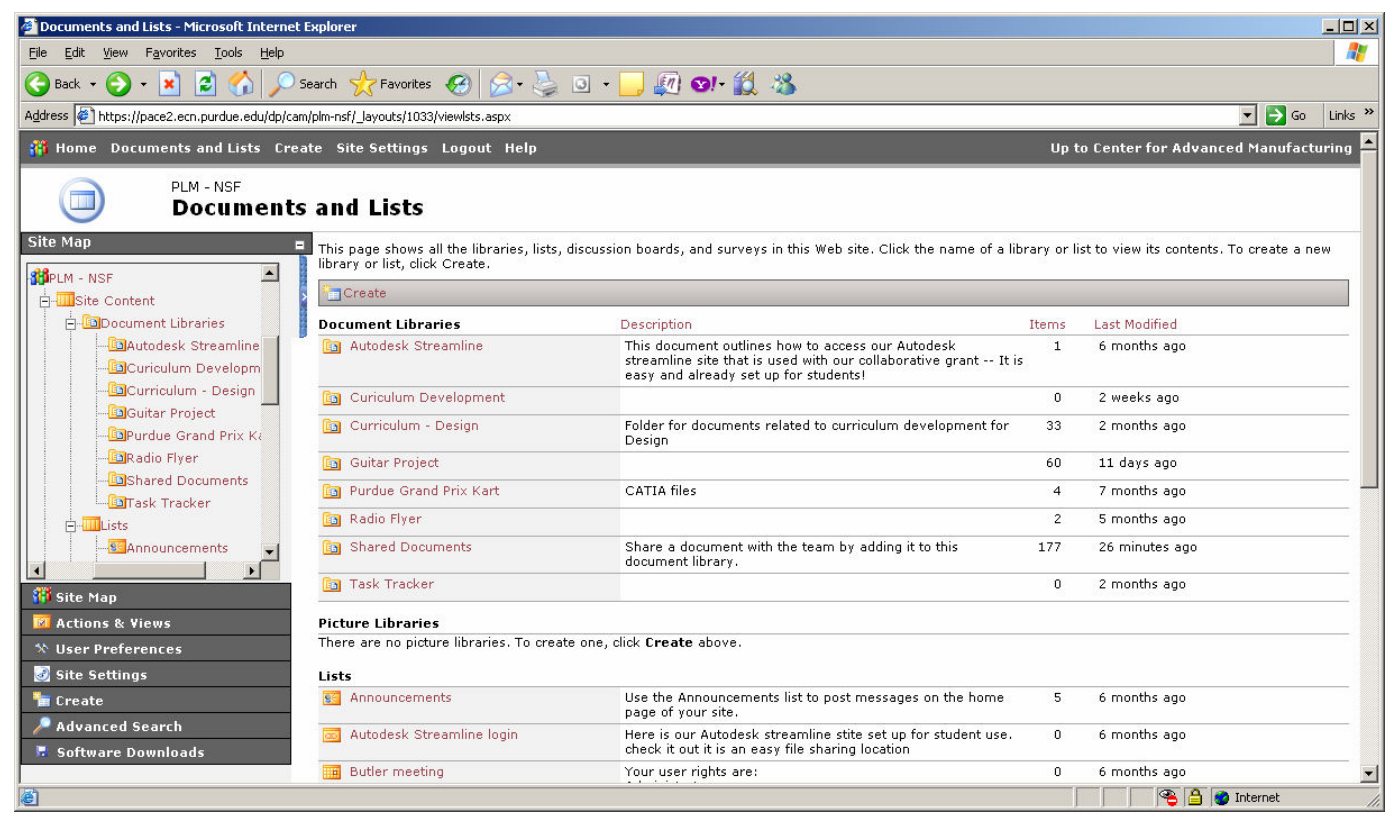

Figure 5: Teamcenter Portal

Integration of these three different file types was tested in various combinations. The final assembly was made in each one of those three software tools, used for part modeling. 
Product Data (STEP) transmits geometry and provides users with the ability to express and exchange digitally useful product information throughout a product's life cycle. Understanding the process of incorporating STEP within a Computer Aided Design program can help engineering managers determine what is involved in adopting STEP in their operations. STEP enables the integration of diverse engineering systems, making it easier for engineers to assemble large product models using component models created in different CAD programs. It can also improve the process of creating models for analysis or manufacturing simulation using a combination of commercial and proprietary codes. Not all neutral exchange data formats have the same results. Different software tools have different file exchange formats. Sometimes geometry can be lost, especially if the part has complicated geometry with curves and surfaces, such as the housing part in this study.

Teams always have diverse members. Their previous background and knowledge about some digital tools like Computer Aided software can be different and on different levels. It is essential to keep this in mind while dividing the tasks. Every team member has to understand exactly what are his or hers responsibilities and deliverables. An achievement of planned goals is closely related to a mutual communication. Assigning task in virtual environment has to be really specific so the designers can understand their limitations, specifications and deliverables. It is also important to keep constant updates if there are any changes in the dimensioning. Ideally, housing should be done last, and some features has to be open for changes. In this case, housing had complex geometry so at the end, some changes were not so easy to implement after the final assembly. Team member are using Adobe connect for their regular online meetings, as shown in Figure 6.

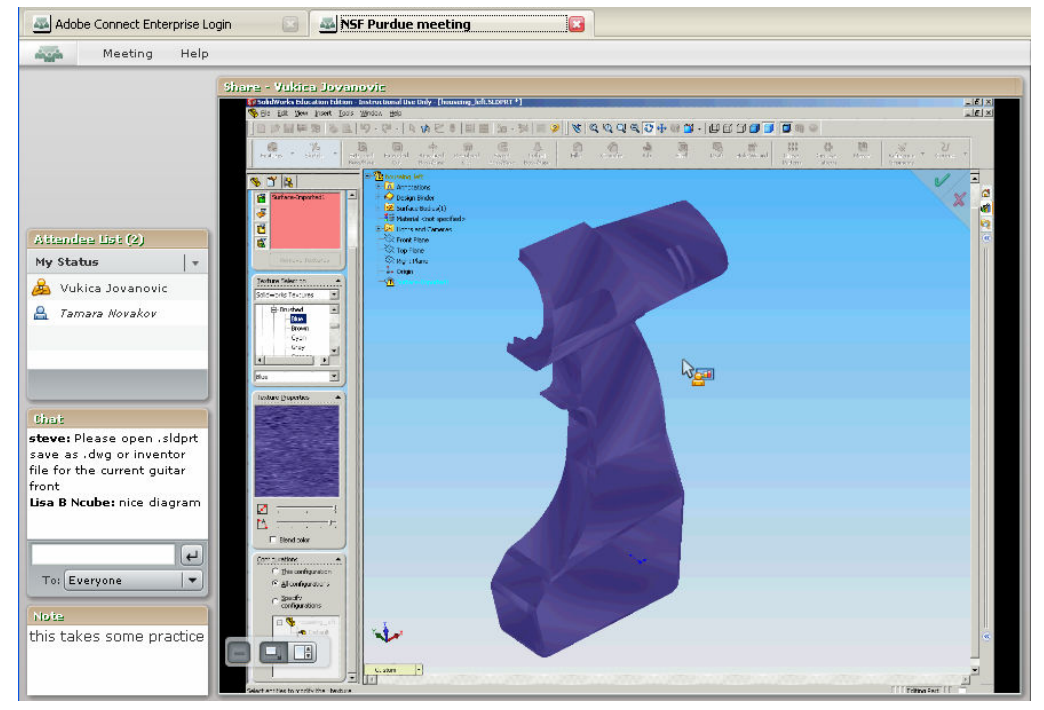

Figure 6: Collaboration in Adobe Connect

The drill housing was later manufactured in Butler County Community College in Butler, Pennsylvania, as shown in Figure 7. 

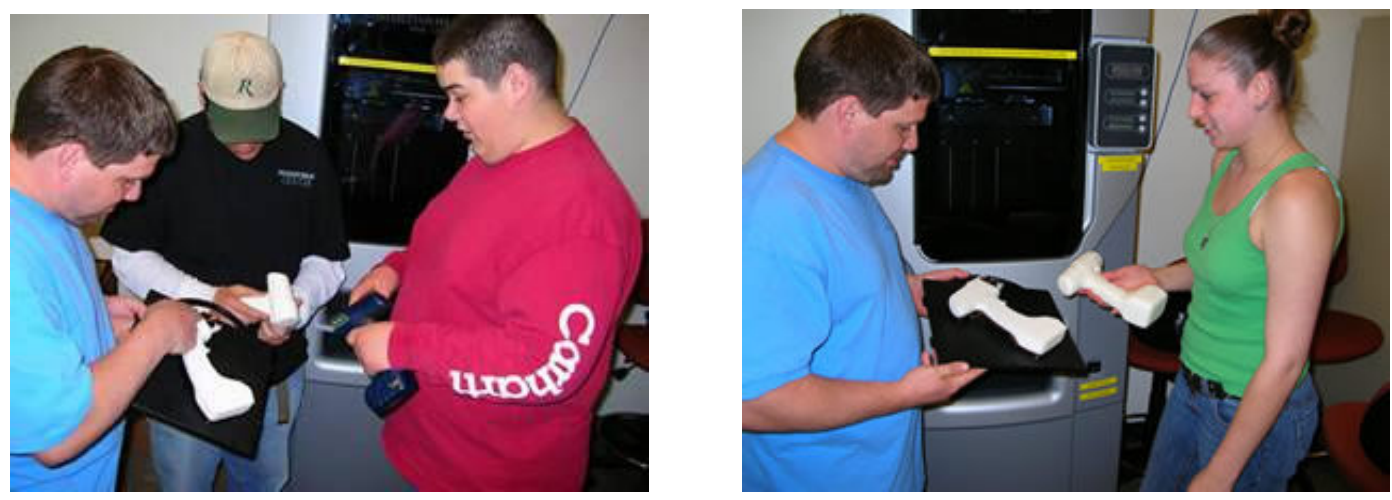

Figure 7: Rapid prototyping of drill housing (Butler County Community College)

\section{The Guitar Project}

During this project, the institutions that are involved in this project were collaborating in order to change the existing design of the guitar for solid body electric to acoustic electric. Existing design was retained. The preamplifier was designed specifically for this instrument. A thin body acoustic guitar is a hybrid instrument that combines the body shape and size of a solid body electric guitar with a flexible soundboard and a thin, hollow body. It is designed to be played only when plugged into an amplifier. The output can be tailored to have tonal properties of either acoustic or electric instruments, making it suitable for a number of different musical styles. This instrument was designed to be easy and inexpensive to produce while still having good sound quality. It will eventually be used as the basis of instrument making workshops for high school students. The explode state of guitar built during this project is given in Figure 8. It has the following components: Neck, Headstock, Freeboard, Electronics, Body, Top, and Bridge.

The teams from different institutions are going to further work on the development of this product through development of curriculum in the same time and product improvements related to the Design for Excellence (Design for Assembly, Design for Sustainability, Design for Reliability, Design for Service and alike) which are defined as some of the twenty key elements of a product realization process ${ }^{12}$.
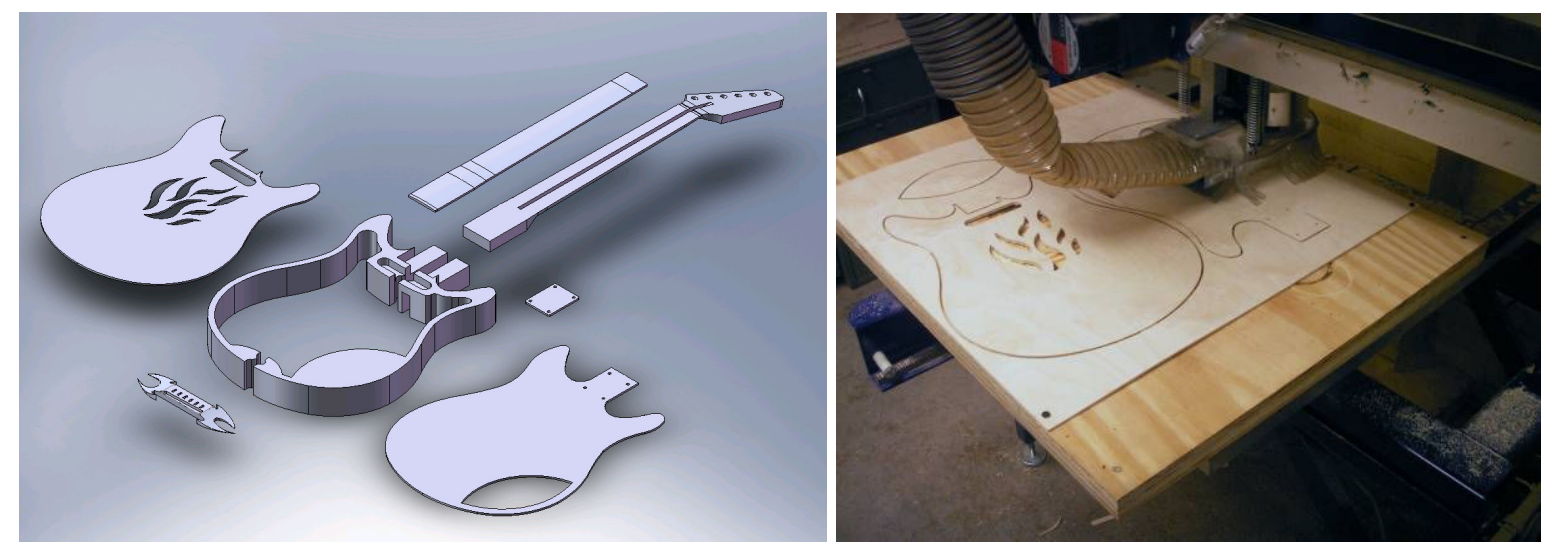

Figure 8: a) Explode state of a electric guitar; b) Machining of the guitar 


\section{Conclusion and Future work}

With this foundation, the project team is developing an interdisciplinary comprehensive design educational program between partner institutions that is addressing transferability of skills and knowledge from associate degree to baccalaureate degree programs. As a part of this, the project team will be developing and delivering educational modules to associate degree technicians, baccalaureate degree technology students, and incumbent workers. An outreach program for high school students will increase the visibility of the engineering and manufacturing profession and academic preparedness among the high school population. The partner institutions are utilizing existing venues for program dissemination including web-based delivery, journal publications, presentations at professional conferences, development of short courses for workforce development, and short programs for high-school students. The broader impacts of the project involve the expansion and improvement of the region's workforce, the dissemination of their instructional material, and the outreach efforts to high school students.

\section{Bibliography}

1. D. J. Skyrme (1997) The Global Knowledge Economy: and its implication for markets, david Skyrme and Associets, Insight No. 21, Retrieved in December 2006: http://www.skyrme.com/insights/21gke.htm

2. R.S. Lee at all (2000) STEP-based product modeling system for remote collaborative reverse engineering, Robotics and Computer-Integrated Manufacturing, Leadership of the Future in Manufacturing, Volume 19, Issue 6, December 2003, pp 543-553.

3. D. S.K. Chan (2003) Simulation modelling in virtual manufacturing analysis for integrated product and process design, Assembly Automation, Volume 23 Number 12003 pp. 69-74

4. Tecnomatix white paper (2005), Digital manufacturing for automotive suppliers: What is the connection between digital manufacturing and business predictability? Retrieved in December 2006: http://www.ugs.com/en_us/Images/wp_tec_auto_supplier_dig_tcm53-4928.pdf

5. J. Stroud (2007) How to manage a distributed workforce, Jim Stroud blog, Retrieved in August 2007 from: < http://jimstroud.com/2007/08/14/how-to-manage-a-distributed-workforce/ >.

6. M. Grives (2007) Virtual Collaboration Rooms, Retrieved on January 2008 from: http://www.purdue.edu/discoverypark/PLM/SME/MW_\%20BT\%20Virtual_Collaboration_Rooms.pdf

7. Teamcenter, Solución definitiva en PLM, La Guia de comprase de Insudtria, Retrieved in December 2006: http://www.interempresas.net/Informatica_Industrial/FeriaVirtual/ResenyaProducto.asp?R=28299

8. Companion to - Standards for Technological Literacy: Content for the Study of Technology, International technology Education Association and its Technology for All Americans Project (ITEA), Advancing Excellence in Technological Literacy, Student Assessment, Professional Development, and Program Standards, Retrieved on January 2008 from: http://www.iteaconnect.org/TAA/PDFs/AETL.pdf

9. Miller, A. (2006) 'Workforce Flexibility: Managing Employees on the Move', Workforce Performance Solutions: the business of talented management, Retrieved in August 2007 from: < http://www.wpsmag.com/content/templates/wps_article.asp?articleid=416\&zoneid=13>.

10. L.Craft (2006) Japan's Slow Moving Tide, PRISM, American Society for engineering Education, December 2006, Volume 16, No 4.

11. M.Lei at all (2007) Data Exchange among Heterogeneous CAD/CAM Systems from a PLM Perspective, Proceedings of ICCPR2007: International Conference on Comprehensive Product Realization 2007 June 18-20, 2007, Beijing, China

12. R.M. French (2008) Engineering the Guitar: Theory and Practice, Springer.

13. BPR Online Learning Center, Twenty Key Elements of a Product Realization Process, Retrieved on December 2006 from: <http://www.prosci.com/prp1.htm>. 